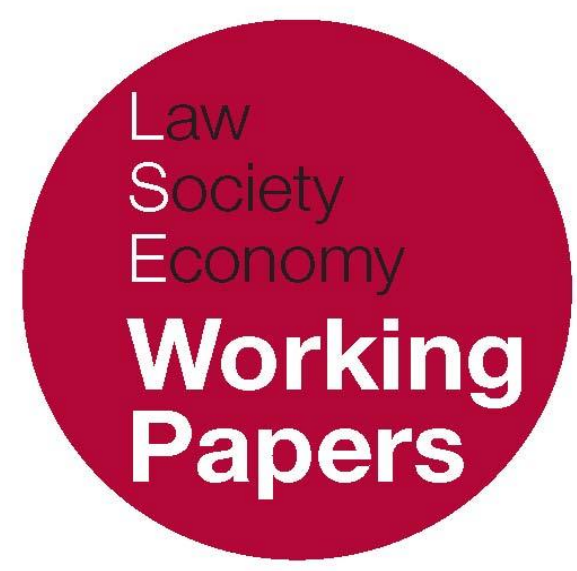

\title{
Sentencing Mentally Disordered Offenders: \\ Conflicting Objectives, Perilous Decisions and Cognitive Insights
}

\author{
Jill Peay \\ LSE Law, Society and Economy Working Papers 1/2015 \\ London School of Economics and Political Science \\ Law Department
}

\begin{abstract}
This paper can be downloaded without charge from LSE Law, Society and Economy Working Papers at: www.lse.ac.uk/collections/law/wps/wps.htm and the Social Sciences Research Network electronic library at: http://ssrn.com/abstract $=2549653$.

(C) Jill Peay. Users may download and/or print one copy to facilitate their private study or for non-commercial research. Users may not engage in further distribution of this material or use it for any profit-making activities or any other form of commercial gain.
\end{abstract}




\title{
Sentencing Mentally Disordered Offenders: Conflicting Objectives, Perilous Decisions and Cognitive Insights
}

\author{
Jill Peay ${ }^{*}$
}

\begin{abstract}
This paper examines the sentencing of mentally disordered offenders using an analysis of s.45A orders under the Mental Health Act 1983. The paper reviews the legislative context of the orders and the relevant tranche of Court of Appeal decisions, and looks at their use since 1998. It then touches on the literature on the role of heuristics and cognitive errors in decision-making as a vehicle for demonstrating why the courts may find sentencing in these cases peculiarly problematic. The paper concludes that partial culpability may be being used as a mechanism for justifying the imposition of these orders which facilitate the application of more risk-averse thresholds of release and recall; but that partial culpability is such a fluid concept as to introduce elements of incoherence into the disposal of mentally disordered offenders.
\end{abstract}

* Professor of Law, London School of Economics and Political Science. 


\section{INTRODUCTION}

The issue on appeal to this court is whether the judge's sentence of custody for life was wrong in principle. It raises once again the complex relationship between custodial sentences and orders under the MHA in relation to an offender who suffers from a mental disorder. ( $R v$ Fort [2013] EWCA Crim 2332 at para 5)

Why should the decision as to whether to punish or treat a convicted offender with mental disorder embody such complexity? In part the answer must lie, as the Court of Appeal was implying, in the intersection between sentencing legislation and the little used provisions under the Mental Health Act 1983 (MHA). But this paper will argue that the major challenge lies in the nature of the task to be undertaken by judges in juggling issues of partial culpability and risk prediction, both of which entail a series of imponderable dilemmas (Hebenton and Seddon 2009, Seddon 2007). Making decisions under such conditions of uncertainty is the essence of much of the literature published on cognitive errors (Kahneman 2012, Tversky and Kahneman 1974). And yet decisions in these most harrowing of cases are made with little legal guidance to judges, but with voluminous clinical evidence, some of which can be contradictory. The decisions will for many offenders entail indefinite sentences of imprisonment or indefinite detention under the MHA; their implications are of the utmost importance for offenders, and arguably also for victims.

This paper attempts to weave an understanding of cognitive factors into the judicial decisions to dispose of or sentence mentally disordered offenders. It is, in many cases, purely a sentencing decision comparable with other complex sentencing decisions. And in such contexts judges have all of the assistance provided by the Sentencing Council's published Guidelines, ${ }^{1}$ and a body of case law. But much less is available when disposing of an offender under the MHA; yet the difficulties here are varied and acute.

In generating an understanding of this tricky area, the paper takes as its starting point decisions concerning the hybrid order, technically known as the hospital and limitation direction, under s.45A of the MHA 1983. Despite the rarity of these orders they provide the basis of the analysis offered here since they represent the peak of complexity. In discussing them, the territory covered will necessarily expand into other MHA disposals and sentencing options, in an attempt to build a synopsis of greater clarity than we currently enjoy. ${ }^{2}$ Moreover, an analysis of these hybrid order decisions sheds light on the wider dilemma for judges when dealing with mentally disordered offenders, namely deciding between

1 Available online at http://sentencingcouncil.judiciary.gov.uk/guidelines/guidelines-to-download.htm.

2 A detailed description of the various mental health options referred to in this paper is available at Ministry of Justice (2008); and a current guide can be found at http://www.cps.gov.uk/legal/1 to o/mentally disordered offenders/. 
hospital and prison. And this decision underpins in part why so many mentally disordered offenders are in prison (Peay 2014); and which in turn contributes to the current disturbing levels of self-harm and suicide in prison. ${ }^{3}$ Thus, a focus on the narrow category of hybrid orders may help us to understand the much larger problem of why so many vulnerable mentally disordered people are to be found within the prison system.

Whether to punish or to treat involves a number of linked inquiries. Establishing what mental disorder or disorders the offender suffers from and with what degree of severity; establishing whether those disorders might be treatable, and if so over what time frame; ascertaining to what extent the criminal behaviour was attributable in whole or in part to the underlying disorder, or not at all; teasing out the effects of any alcohol or drugs on the offender, and/or the effects of prescription medication; estimating the likelihood of future offending in the context of past offending and the offender's uncertain treatability; ascertaining an offender's motivation where there may be little or no reliable understanding given his or her mental state; addressing issues of risk, and doing so in the context of what may be exceptionally grave and emotive index offences; thinking about methods of release many years in the future by different bodies with different thresholds and criteria for release; considering the nature of those bodies' decision-making tasks and of offender-patients receiving different levels of support in the community according to the method of release; and of differing criteria for recall depending on the method of release should an individual's behaviour or mental state deteriorate in the community. All of these are issues that may go through a judge's mind. Not all of them are equally legally relevant to the task at hand. And, of course, the relative rarity of these decisions about convicted mentally disordered offenders at the high end of the spectrum of seriousness and risk means there are only a limited number of precedents to guide a judge; and that those there are, are unlikely, given the numerous criteria above, to be sufficiently relevant to give the judge confidence. Finally, the reported cases from the Court of Appeal are understandably confusing where offenders have appealed, often years later, when they may have been subject to treatment and matters have emerged that could or might have influenced earlier sentencing. ${ }^{4}$

But that is not the end of the difficulties. As Kahneman and Tversky observed in 1984:

Making decisions is like speaking prose - people do it all the time, knowingly or unknowingly........The study of decisions addresses both normative and

\footnotetext{
3 See http://www.theguardian.com/society/2014/oct/21/prisons-inspector-suicide-understaffingovercrowding-mental-health-vulnerable-inmates; http://www.theguardian.com/society/2014/nov/13/mentally-disturbed-prisons-matthew-williamshealth-services? $\mathrm{CMP}=$ share btn link.

${ }^{4}$ See, for example, $R v$ Anderson (Darren Gabriel) (2013) EWCA Crim 2212 and R $v$ Haddon [2004] EWCA Crim 1201. A s.45A order would have been made in the latter case had a bed been available to admit this personality disordered prisoner within 28 days of the case being heard on appeal. The CA heard that a bed was unlikely to be available for the next six months.
} 
descriptive questions. The normative analysis is concerned with the nature of rationality and the logic of decision making. The descriptive analysis, in contrast, is concerned with people's beliefs and preferences as they are, not as they should be. The tension between normative and descriptive considerations characterizes much of the study of judgment and choice. ${ }^{5}$

Yet as Kahneman (2012) illustrates, drawing in large measure on his earlier work with Tversky $(1974,1981,1984)$ people are very good instinctive decision-makers in some circumstances, but remarkably poor in others. Decisions are prone to all sorts of cognitive and emotional biases; and the heuristics that serve us well in some circumstances mislead us in others (see Kahneman 2012: 416). And yet the cognitive literature indicates that we all have excessive confidence in our own abilities, something which is likely to facilitate not obviate error. Decisions involving the substance of those posed in sentencing mentally disordered offenders may be peculiarly prone to certain kinds of biases.

Before embarking on this, two words of caution are necessary. First, there is no definitive list of s.45A cases. The cases discussed in this paper result from a Westlaw search and cross referencing with the Mental Health Law Online resource. ${ }^{6}$ Both result in over-inclusion of cases where s.45A was not a live issue, and potential under-inclusion of actual s.45A appeals. As Table 1 below illustrates, few such orders have been made since their inception in October 1997, when they were confined to offenders suffering from psychopathic disorder (Eastman and Peay 1998). Even the extension of their remit by the Mental Health Act 2007 to cover all forms of mental disorder has had only a marginal effect on their usage, albeit in the last three years there has been a notable increase. ${ }^{7}$

The figures are somewhat confusing as the Health and Social Care Information Centre (HSCIC) and the National Offender Management Service (NOMS) data, published by the Ministry of Justice, use different accounting periods and different census days. They also do not count patients in the same way. The NOMS census data on the number of detained patients are reliable, in that they are derived from an electronic case-working system which tracks the progress of all restricted patients (see Table 2 below). The HSCIC data are based in part on returns from individual hospitals, and, as their publication notes, are not complete. Whilst they have striven to improve their accuracy, ${ }^{8}$ this is in turn undermined by a failure of some parts of the Independent Sector to submit data. ${ }^{9}$ The Independent Sector providers are notably responsible for the care of over a quarter of detained patients. The NOMS data also publishes a caveat: their figures

\footnotetext{
${ }^{5}$ Kahneman and Tversky (1984: 341).

${ }^{6}$ Available online at http://www.mentalhealthlaw.co.uk/Main Page.

7 This came into effect in November 2008.

8 HSCIC (2013) at p.3

${ }^{9}$ HSCIC (2013) at p.6.
} 
include those admitted more than once in a year, so will potentially over-count patients.

However, the other set of figures in Table 2 on the small number of detained patients with s.45A orders supports the argument that very few of these orders have ever been made. It should be stressed that the detained figures are not simply a running total of the orders made; whilst offender patients are by and large held for lengthy periods, some patients are transferred to prison and are thereby lost to the numbers of detained in-patients. Moreover, in some of the appealed cases the s.45A order is quashed because it has been wrongly imposed on an offender under 21. This also contributes to the disparity between the number of orders made, and the number of people detained subject to them. But what the statistics do is to throw into stark relief the contentious nature of the orders, given the seemingly disproportionate number of appeals recorded and discussed below.

It should also be stressed that taking the figures of s.45A orders at their highest (NOMS figures for 2013 of 18 admissions and a total of 46 detained patients) and comparing them with the overall number of restriction order patients does highlight the rarity of s.45A cases and their marginality within the detained offender patient population. Specifically, hospital orders with restrictions (s.37/41 ${ }^{10}$ made by the Courts in 2013 totalled 294; and the number of transfers of untried/unsentenced prisoners with restrictions (s.48/49) totalled 533; and of sentenced prisoners with restrictions there were 457 (s.47/49). ${ }^{11}$ At the census point in 2013 there were 4,449 detained restricted patients. ${ }^{12}$

\footnotetext{
10 This is an order for indefinite detention in a psychiatric hospital. Discharge can be ordered, either absolutely (which is rare) or conditionally by the Mental Health Tribunal or by the Secretary of State for Justice. The latter's powers are managed on a day to day basis by the specialist Mental Health Unit at the Ministry of Justice.

${ }^{11}$ See Table 6 of the Offender Management Annual Tables 2013.

${ }^{12}$ See Table 2A of the Offender Management Annual Tables 2013.
} 
Table 1: s.45A - admissions by year of patients formally detained ${ }^{13}$

\begin{tabular}{|c|c|c|c|c|c|c|c|}
\hline 1998 & 1999 & 2000 & 2001 & 2002 & 2003 & 2004 & 2005 \\
\hline 0 & 8 & 3 & 3 & 3 & 4 & 2 & 2 \\
& & & & $(3)^{14}$ & $(4)$ & $(2)$ & $(2)$ \\
\hline
\end{tabular}

\begin{tabular}{|c|c|c|c|c|c|c|c|c|}
\hline $2005 / 6$ & $2006 / 7$ & $2007 / 8$ & $2008 / 9$ & $09 / 10$ & $2010 / 1$ & $2011 / 2$ & $2012 / 3$ & $13 / 14$ \\
\hline 1 & 12 & 11 & 3 & 5 & 1 & 8 & 3 & $2^{15}$ \\
$(4)$ & $(5)$ & $(2)$ & $(5)$ & $(11)$ & $(19)$ & $(14)$ & $(18)$ & \\
\hline
\end{tabular}

Table 2: s.45A - census of detained patients by year at 31 2008;16 census of detained patients at 31 st December 2009-201317

\begin{tabular}{|l|l|l|l|l|}
\hline 1998 & 1999 & 2000 & 2001 & 2002 \\
\hline 0 & 5 & 7 & 10 & 9 \\
\hline
\end{tabular}

\begin{tabular}{|l|l|l|l|l|}
\hline 2003 & 2004 & 2005 & 2006 & 2007 \\
\hline 11 & 10 & 11 & 14 & 16 \\
\hline
\end{tabular}

\begin{tabular}{|l|l|l|l|l|}
\hline 2008 & 2009 & 2010 & 2011 & 2012 \\
\hline 13 & 16 & 19 & 32 & 30 \\
\hline
\end{tabular}

\begin{tabular}{|l|l|l|l|l|}
\hline 2013 & & & & \\
\hline 46 & & & & \\
\hline
\end{tabular}

${ }^{13}$ These figures are derived from HSCIC (2013) and prior annual publications in the series for the figures from 2005-6 to the current year. Available online at http://www.hscic.gov.uk/catalogue/PUB12503/inpdet-m-h-a-1983-sup-com-eng-12-13-rep.pdf. Figures from before 2005 come from the Ministry of Justice (2010) Statistics of Mentally Disordered Offenders 2008, and prior sequence. Available online at https://www.gov.uk/government/statistics/statistics-of-mentally-disordered-offenders-ns.

${ }^{14}$ Figures in brackets are the admission figures derived from the NOMS Offender Management Annual Tables, Restricted Patients, Table 6. Available online at https://www.gov.uk/government/statistics/offender-management-statistics-quarterly-octoberdecember-2013-and-annual and prior sequence.

15 Taken from HSCIC (2014).

16 These figures show the number of patients detained on the annual census day $31^{\text {st }}$ March (Ministry of Justice 2010) and prior annual publications, until the publication ceased in 2010.

17 For the years 2009-2013 the figures can be found at https://www.gov.uk/government/statistics/offender-management-statistics-quarterly-octoberdecember-2013-and-annual - see Restricted Patients 2013 Table 4. Table 4a reveals that of 46 detained s. $45 \mathrm{~A}$ patients, 44 were men. 
The second word of caution is that it is often easier to criticise those undertaking a difficult and skilled task than it is to do the task oneself. In the light of the above discussion few would envy the judge's position in deciding on these cases. But the literature on decision-making recognises that doing a task also makes one cognitively busy and thus less open to new information which perhaps ought to be taken into account (Kahneman 2012: 417). A neutral observer should be more able to process such new information.

And one final word on terminology. The use of the term 'to dispose' in this paper is intentional: for when a judge sends a mentally disordered offender to hospital this is not strictly a sentencing decision. To sentence, according to the Oxford English Dictionary, is to declare the punishment allocated to a person condemned in a criminal trial. And offenders are not sent to hospital for punishment. Punishment is an option for those convicted offenders who have mental disorder; and it is frequently the option of choice as the make-up of our prison population, standing at around 86,000 in November 2014, reveals (Peay 2014). ${ }^{18}$ For those convicted of murder, a sentence of imprisonment for life is the only possible sentence. Apart from murderers, convicted offenders who are mentally disordered at the point of sentence can be sent to prison, or can be sent to hospital for treatment. In the latter circumstances where a judge chooses, for example, to impose a hospital order with restrictions under the Mental Health Act 1983 (a section 37/41 order), it is formally a decision to impose no punishment; and it would be a curious scenario to sentence someone to no punishment. There are, of course, also a small number of alleged offenders each year who are found not guilty by reason of insanity (ngri). They have not been convicted and therefore cannot be punished; a therapeutic disposal is for them the only option. They are not the subject of this paper.

\section{THE HOSPITAL AND LIMITATION DIRECTION: S.45A MHA 1983}

This order, commonly referred to as the hybrid order, permits the courts to sentence an offender to a period of imprisonment, but simultaneously direct that he or she be immediately admitted to hospital for a period of treatment. If the treatment proves unsuccessful, or indeed successful, the offender can be returned to prison to complete the sentence of imprisonment. This acts as a safety-net for anxiety about the early or premature release of those who could no longer be justifiably detained in hospital.

As noted in the Tables above the hybrid orders have been used rarely. In part this is due to the requirement that the court first considers, and then rejects, the possibility of a hospital order (s.37), or a hospital order with restrictions (s.37/41).

18 On the $28^{\text {th }}$ November 2014 the figure was 85,902; see http://www.howardleague.org/weekly-prisonwatch/. 
These disposals will rightly divert most of those who would otherwise be eligible for a hybrid order, on grounds of the severity of their disorders together with the necessity to protect the public from serious harm. Second, the courts have to come to the conclusion that a sentence of imprisonment, rather than a community order (which can include a community order with a mental health component) is the only way of dealing with an offender. Then, finally, they can reconsider whether an initial hospital disposal might be appropriate; and if so, make the s.45A order.

Section $45 \mathrm{~A}$ is remarkably uninformative as to its objectives. In the logical space between a s.37/41 order and imprisonment (and this is a choice for the judge, since the decision to impose or reject a restriction order can be made against medical advice, even unanimous medical advice) ${ }^{19}$ must lie some concern about the mentally disordered offender either deserving an element of punishment (see R $v$ Birch 1989 below) or (and/or) a concern that somehow the medical regime is insufficiently protective against the risk of future serious offending. The latter concern is curious since the s.37/41 order allows considerable scope for detaining those with a disorder who remain a danger, ${ }^{20}$ leaving only the 'problem' of offenders whose disorders are 'cured' but who remain independently dangerous. In any event, both backward and forward looking concerns, about the need to punish offenders with mental disorder and the need to ensure protection against future offending, could be addressed through the use of imprisonment with a s.47 MHA transfer order, albeit the latter decision involves the Secretary of State and is not an exclusively judicial decision. So what purpose would the s.45A order be serving?

In 1998 Eastman and Peay (p.108) called for orders under s.45A MHA to be closely monitored. In order to undertake this exercise, some prior understanding of its chequered history is required.

\section{S.45A - HISTORY AND OBJECTIVES}

The hinterland is convoluted. The hybrid order had a prolonged genesis, in part because it attempted to tackle a problem which had proven problematic to remedy. In short, what do you do with offenders whose underlying disorder is thought to make them prone to offend and yet that disorder may not be readily treatable? If you send them to prison you do nothing to address the potential cause of their offending. And if a sentencer tries to make allowance for the extent to which an offender's responsibility for the offence may have been reduced in part because of their disorder by reducing the sentence length, this may in turn increase anxiety about the rapidity with which an offender may be returned to the

${ }^{19} \mathrm{R} v$ Royce (1981) 3 Crim LR 58.

20 Anderson, Reid and Doherty v Scottish Ministers Privy Council [2001] UKPC D5; Hutchison Reid v UK (2003)

37 EHRR 211. 
community to reoffend. But if such offenders receive a hospital disposal and prove not to be treatable, and still remain a high risk for offending because of their disorder, then doctors are turned into gaolers and hospitals in warehouses.

The origins of the hybrid order lie in the Report of the Reed Committee (1994), which cautiously recommended the introduction of such an order for those suffering from psychopathic disorder who were thought to be of uncertain treatability. The hybrid order would allow practitioners to have a 'therapeutic go' with an offender in hospital, but if their efforts proved unsuccessful they could transfer the offender to prison and avoid becoming locked into a long-term nontherapeutic relationship. This therapeutic justification was the first of a number of justifications.

By 1996 the thinking had turned and both the Home Office/Department of Health (1996a) discussion paper and the White Paper embraced the notion of the need for a punitive element in the disposal 'to reflect the offender's whole or partial responsibility' (Home Office/Department of Health 1996b para 1.4). The White Paper in its chapter on Sex Offenders and Mentally Disordered Offenders (groups which were then routinely linked together) detailed the policy in paras 8.12 to 8.14 , stressing the need for flexibility, the offender's need for treatment, the demands of justice, the right of other people to be protected from harm, and the need to serve a fixed term in prison to reflect the offender's significant responsibility for the offence notwithstanding the disorder, or because the link between the offending behaviour and the disorder was not clear at the time of sentencing. At the time of the White Paper in 1996 the government was considering making the order available for offenders suffering from all types of mental disorder.

Paragraphs 8.12 to 8.14 are set out in full here as they are regularly cited in the s.45A Court of Appeal cases discussed below.

8.12. The Government proposes changes in the arrangements for the remand, sentencing and subsequent management of mentally disordered offenders to provide greater protection for the public and to improve access to effective medical treatment for those offenders who need it. The central change, if adopted, would be the provision of a 'hybrid order' for certain mentally disordered offenders for whom the present form of hospital order is unsatisfactory, particularly those who are considered to bear a significant degree of responsibility for their offences. The order would enable the courts, in effect, to pass a prison sentence on an offender and at the same time order his immediate admission to hospital for medical treatment.

8. 13. The hybrid order, together with other proposals amending the detail of the Mental Health Act 1983, would substantially increase the flexibility of arrangements for dealing with mentally disordered offenders at all stages from remand through to rehabilitation. In particular, it would enable the courts to deal with some of the most difficult cases in a way which took 
proper account of the offender's need for treatment; the demands of justice; and the right of other people to be protected from harm.

8. 14. Existing sentencing arrangements for offenders who are mentally disordered require the court to decide either to order the offender's detention in hospital for treatment, or to sentence him to imprisonment, or to make some other disposal. In some cases, an offender needs treatment in hospital but the circumstances of the offence also require a fixed period to be served in detention. This may be because the offender is found to bear some significant responsibility for the offence notwithstanding his disorder, or because the link between the offending behaviour and the mental disorder is not clear at the time of sentencing. The hybrid disposal would be a way of enabling the requirements of sentencing in such cases to be met. Under the order, an offender would remain in hospital for as long as his mental condition required, but if he recovered or was found to be untreatable during the fixed period set by the court, he would be remitted to prison. The hybrid order was recommended for use in sentencing offenders suffering from psychopathic disorder by the Department of Health and Home Office Working Group on Psychopathic Disorder. The Government is considering whether it might be made available in respect of offenders suffering from all types of mental disorder currently covered by mental health legislation.

In the event, when s.46 of the Crime (Sentences) Act 1997 was passed, (which introduced the hybrid order by amending the $1983 \mathrm{MHA}$ ), it applied solely to offenders suffering from psychopathic disorder; and those offenders had to be deemed treatable, thereby removing the advantage of 'uncertain treatability' which the Reed Committee had envisaged. The hybrid order, s.45A MHA, was accompanied by a Home Office circular (52/1997) which stressed neither uncertain treatability nor the need to reflect partial culpability. Rather, the justifications were explained in paragraph 3 as being 'to give the courts greater flexibility' where prison was thought to be appropriate in spite of evidence that the offender was mentally disordered. ${ }^{21}$ This might arise either where the offender would otherwise have received an automatic life sentence under the new mandatory provisions introduced in s.2 of the Crime Sentences Act (these second strike automatic life sentences were abolished in April 2005 when the Indeterminate Sentence for Public Protection [IPP] was introduced; the IPP has now also been abolished) or because the court was satisfied that a prison sentence with a hospital direction was the most effective way to protect the public from harm. And, sotto voce, the latter was arguably the most telling policy proposal. If an offender's offence did not merit a long prison sentence, yet he was thought likely to reoffend because of the nature of his underlying disorder, then he could

${ }^{21}$ Home Office Circular 52/1997 Crime (Sentences) Act 1997, Mental Health Unit. 
be held in hospital all the time that disorder persisted. And if it did merit a long sentence, and the disorder did not persist, then he could be detained in prison up until the expiry of his prison sentence; and with a growing emphasis on indeterminate or life sentences, that could be for a very long time, since release here is determined on the basis of risk. ${ }^{22}$

Understanding the role of the hybrid order is thus problematic because its objectives and its scope have changed; indeed, they changed even as it achieved its final legislative form (Eastman and Peay 1998: 96-98). Despite this altered justification the Court of Appeal has repeatedly made reference to the earlier White Paper framework for the hybrid order (Home Office/Department of Health 1996b). ${ }^{23}$ And this confusion is redolent of the difficulties that have bedevilled the use of the hybrid order.

It is also telling that the hybrid order was introduced in the same statute that introduced the controversial automatic life sentence for a second serious offence. This sentence was also discussed in the same White Paper in which it was noted that the courts were making too little use of the discretionary life sentence (1996b: para 10.4) noting the great advantage of the life sentence was that it could take account of the whether the offender could be safely released at the end of the tariff period. Determinate sentences did not have that advantage. Victims were to be protected from persistent violent and sexual offenders by requiring the courts to impose an automatic life sentence in particular circumstances (1996: para 10.11).

These paragraphs are also set out in full here.

10.4. The great advantage of the life sentence is its flexibility. It recognises that there are two separate considerations: the length of time the offender should serve as punishment for the offence he or she has committed (the tariff), and the question whether he or she can safely be released at the end of that period. However courts make very little use of the discretionary life sentence. In 1994, for example, 434 offenders were convicted of rape or attempted rape, but only 12 were sentenced to life imprisonment. In 1994, 217 offenders were convicted of a second serious violent or sexual offence, but only 10 received a discretionary life sentence.

10.5. This does not necessarily mean that the sentences imposed on violent and sex offenders are too lenient: long sentences are frequently imposed on offenders convicted of violent and sex offences [...] But if a determinate sentence is imposed the offender must be released once that sentence has been served, even if there is every reason to believe that he or she will

22 The Parole Board is under a duty to release, once an offender has passed their tariff date, where they are satisfied that it is 'no longer necessary for the protection of the public that the prisoner should be confined' (s.28 (6)(b) Crime (Sentences) Act 1997).

${ }^{23}$ See e.g. $\mathrm{R} v$ Drew HOL, $\mathrm{R} v$ Staines, $A G$ Reference 2011 and in $\mathrm{R} v$ Cooper and $\mathrm{R} v$ Fox (both cases where a 1999 date was given for the White Paper), all discussed below. 
commit further serious offences. That has led to a number of tragic cases where offenders convicted of violent or sex offences have been released only to repeat their offences almost immediately.

10.6. It is essential that the public receives proper protection from serious, dangerous and persistent offenders. Long sentences are not sufficient, of themselves, to provide that protection: before potentially dangerous offenders are released an assessment must be made to see whether they still pose a risk. If an offender cannot safely be released he or she must continue to be detained - if necessary indefinitely.

The chapter concluded:

10.11. Too often in the past, those who have shown a propensity to commit serious violent or sex offences have served their sentences and been released only to offend again. In many such cases, the danger of releasing the offender has been plain for all to see - but nothing could be done, because once the offender has completed the sentence imposed, he or she has to be released. Too often, victims have paid the price when the offender has repeated the same offences. The Government is determined that the public should receive proper protection from persistent violent or sex offenders. That means requiring the courts to impose an automatic indeterminate sentence, and releasing the offender if and only if it is safe to do so.

Thus, what was portrayed as an underuse of discretionary life sentences, and the consequent danger that could arise where an offender was released from a determinate sentence, would be tackled in two ways. First, through the introduction of mandatory automatic life sentences for a second serious offence: only in truly exceptional cases would the automatic life sentence not be given. Second, through the hybrid order; since persistent violence could arise either from mere criminality or an enduring underlying mental disorder, then those with mental disorder needed to be brought under the same protective umbrella if the clinicians were wrong about their responsiveness to treatment. There was to be a renewed legislative emphasis on risk, with the clear intention of protecting the public from harm.

As time has passed, and as the cases below document, partial culpability has come back to the forefront of the court's reasoning. Even to the extent, as will emerge below, where concepts of diminished responsibility (technically confined to those charged with murder) pepper the courts' reasoning when dealing with mentally disordered offenders. Moreover, there has been a growing concern about methods of release and recall arrangements, which can be traced back to the House of Lords decision in Drew [2003] 1 WLR 1213, and which is consistent with the risk prevention agenda in the White Paper. 
Finally, following the 2007 Mental Health Act, the ambit of the order has been extended to embrace all offenders suffering from any kind of mental disorder, provided it is of the requisite nature and degree to merit hospital admission. In short, there has been a shift from a limited initiative to treat (with a safety net of prison) a small group of defined offenders, to an all embracing order which looks far into the future and attempts to manage risk, which is itself an uncertain concept, whilst juggling with issues of partial culpability, in themselves so ineffable as to defy evaluation.

\section{R V DREW [2003] 1 WLR 1213 HOUSE OF LORDS}

In Drew, a case which dealt with an offender who fell within the new automatic life sentence provisions and accordingly was sent direct to prison despite his acknowledged severe mental illness, the House of Lords reviewed the relationship between the MHA disposals and the automatic life sentence. Whilst recognising that Drew's mental health deteriorated during the eight days he was in prison before his transfer back to hospital could be effected, they nonetheless concluded that this did not constitute a breach of article 3 of the European Convention on Human Rights (ECHR).

In so doing they noted with surprise that the new hybrid order would be the potential solution, but for the fact that it applied only to those, in England and Wales, suffering from psychopathic disorder:24 and Drew had mental illness. They cited the White Paper paragraphs as acknowledging the problem they faced:

The second problematical situation arises where neither a sentence of imprisonment nor a hospital order, on its own, appears appropriate in the case of a particular offender and where the mutually exclusive operation of such disposals appears unsatisfactory. (para 13)

Drew had pleaded guilty to an offence where an essential ingredient was an intention to cause grievous bodily harm to another. Thus, '[T] he appellant's mental illness could properly be relied on as mitigating the criminality of his conduct but not as absolving him from all responsibility for it'. (para 16). Accordingly, it was not wrong in principle to pass a sentence of imprisonment. Moreover, in order to dispose of the offender under s.37 MHA this had to be 'the most suitable method of disposing of the case'. Thus, the judge had discretion not to impose a s. 37 order. As the House of Lords further observed:

The Court of Appeal in R v Birch(1989) 11 Cr App R (S) 202, 215, pointed out that prison might be chosen as an alternative to hospital either because the offender was dangerous and no suitable secure hospital accommodation

24 There was no such limitation as enacted in Scotland, where the provision applied to any form of mental disorder. 
was available or because there was an element of culpability in the offence which merited punishment, as might happen where there was no connection between the mental disorder and the offence or where the offender's responsibility for the offence was reduced but not wholly extinguished. (para 16)

And since the power to transfer the offender from prison to hospital existed under s.47 of the MHA, and since the Home Secretary was obliged to act compatibly with the Convention, there would be no need for the offender to stay unnecessarily in prison and suffer 'humiliation, distress and deterioration of his mental condition'; suffering which could properly be regarded as inhuman or degrading treatment or punishment under Article 3 of the ECHR.

In rejecting the appeal, the House of Lords made one further observation:

In the course of his argument for the Home Secretary, Mr Perry gently suggested that Court of Appeal decisions generally encouraging the making of hospital orders where the relevant medical criteria were met might, in the absence of adversarial argument, have given less than adequate weight to the differing conditions governing the release and recall of restricted patients as opposed to life sentence prisoners. He instanced authorities such as R v Howell (1985) 7 Cr App R (S) 360; R v Mbatha (1985) 7 Cr App R (S) 373; R v Mitchell [1997] 1 Cr App R (S) 90; R v Hutchinson [1997] 2 Cr App $\mathrm{R}(\mathrm{S})$ 60. There may be some force in this criticism, and we would accept that these differing conditions are a matter to which sentencing judges and appellate courts should try to give appropriate weight. The difficulties caused to prison managements by the presence and behaviour of those who are subject to serious mental disorder are, however, notorious, and we would need to be persuaded that any significant change in the prevailing practice was desirable. (para 22, emphasis added)

In so doing, the House of Lords not only set running the arguments about release and recall following MHA disposal or life sentences as matters to which sentencing judges should try and give appropriate weight, but they also intimated how difficult it could be to house mentally disordered offenders in prison; and thus of their need to be persuaded of a shift in emphasis from hospital to prison. Hence the cautionary words went in both directions.

\section{The Court of Appeal Cases}

In reviewing these cases it is important to remember that the Court of Appeal can only interfere with a sentence if it was unlawful, wrong in principle or manifestly excessive. Thus, there may well be cases where the court was less than content with the decision made, but nonetheless was constrained from interfering. In 
order to help situate the cases a chronology is set out below, but it is evident from reading the cases that citation of other s.45A cases is not common; and that some ambiguities have entered the courts' reports as a consequence of reliance on previous judgments (for example, the White Paper issues).

Table 3 The appealed cases: chronological order of cases discussed

\begin{tabular}{|c|c|c|}
\hline R v Staines [2006] EWCA Crim 15 & $\begin{array}{l}\text { Manslaughter } \\
\text { Diminished responsibility }\end{array}$ & $\begin{array}{l}\text { Discretionary life } \\
\text { sentence, } 4 \text { years, } \\
\text { s. } 45 \mathrm{~A}\end{array}$ \\
\hline R $v$ House [2007] EWCA Crim 2559 & $\begin{array}{l}\text { Attempted murder, } \\
\text { attempted rape, indecent } \\
\text { assault }\end{array}$ & $\begin{array}{l}\text { Discretionary life } \\
\text { sentence without tariff, } \\
\text { s.45A }\end{array}$ \\
\hline R $v$ Cooper [2010] EWCA Crim 2335 & $\begin{array}{l}\text { Diminished responsibility } \\
\text { manslaughter, attempted } \\
\text { murder }\end{array}$ & $\begin{array}{l}2 \times \operatorname{IPP}(6 \text { and } 4.5 \text { years }), \\
\text { s. } 45 \mathrm{~A}\end{array}$ \\
\hline $\begin{array}{l}\text { Attorney-General's Reference No } 54 \text { of } 2011 \\
\text { [2011] EWCA Crim } 2276\end{array}$ & $\begin{array}{l}\text { Unlawful act } \\
\text { manslaughter }\end{array}$ & s.37/41 MHA \\
\hline R v Fox [2011] EWCA Crim 3299 & $\begin{array}{l}\text { Kidnapping, s.18 OAPA } \\
\text { (gbh with intent) }\end{array}$ & IPP (8 years), s.45A \\
\hline R v Jenkin [2012] EWCA Crim 2557 & $\begin{array}{l}\text { s.18 OAPA } 1861 \text { (gbh } \\
\text { with intent) }\end{array}$ & $\begin{array}{l}\text { Discretionary life } \\
\text { sentence (6 years), s. } 45 \mathrm{~A}\end{array}$ \\
\hline Rv Stead [2012] EWCA Crim 92 & $2 \mathrm{x}$ sexual assault & $\begin{array}{l}10 \text { years detention YOI, } \\
\text { s. } 45 \mathrm{~A}\end{array}$ \\
\hline $\mathrm{R} v$ Ruby [2013] EWCA Crim 1653 & $\begin{array}{l}3 \mathrm{x} \text { wounding with intent } \\
\text { OAPA } \\
2 \mathrm{x} \text { threats to kill }\end{array}$ & $\begin{array}{l}\text { IPP, s.45A } \\
\text { IPP, s.45A }\end{array}$ \\
\hline R v Fort [2013] EWCA Crim 2332 & $\begin{array}{l}\text { Diminished responsibility } \\
\text { manslaughter }\end{array}$ & $\begin{array}{l}\text { Custody for life (4 } \\
\text { years), s. } 45 \mathrm{~A}\end{array}$ \\
\hline R v Poole [2014] EWCA Crim 1641 & Conspiracy to steal & $\begin{array}{lr}18 & \text { months } \\
\text { imprisonment, } & \text { s.45A, } \\
\text { confiscation } & \text { order } \\
£_{143.25,} & \text { Victim } \\
\text { Surcharge order } & £ 100\end{array}$ \\
\hline
\end{tabular}

\section{UNLAWFUL CASES}

In three cases, Stead, Ruby and Fort, young offenders were given a s.45A order. This was unlawful since s.45A can only attach to a sentence of imprisonment and those under 21 cannot receive imprisonment but rather are detained in Young Offender Institutions (YOI). All three cases occurred after the $A G$ Reference case 
in 2011 in which the Court of Appeal bemoaned the fact that s.45A did not apply to young offenders, and urged that consideration be given to its extension to that group.

It is also interesting that all three cases show the courts acting with a clear therapeutic intention with what were regarded as vulnerable young offenders for whom a prison environment was thought to be detrimental. Two of the offenders had autistic conditions and the third, Fort, was a case of first incidence psychosis. In all three a clear link was deemed present between the offence and the underlying disorder (albeit in Stead there was a previous conviction for arson).

Stead is perhaps the most curious since here the error is made by the Court of Appeal and not by the trial judge, and is indicative of the level of confusion which can be present in these cases; and one might add, the waste of judicial time and resources entailed. Stead was convicted on two counts of sexual assault, including the anal rape of a 15 year old when posing as a security guard; and pleaded guilty to a charge of perverting the course of justice. He had a previous conviction for arson. He was sentenced to 10 years detention in YOI plus an indefinite Sexual Offences Prevention Order (SOPO), despite the psychiatric evidence that a hospital disposal was most appropriate. The psychiatrist who gave evidence to the court was offering a placement in a low secure setting on the basis that Stead would be given a s.37 order; the judge was also aware of the possibility of adding a s.41 restriction order. Whilst the judge did not formally find him to be 'dangerous' under the CJA 2003, there was a pre-sentence report which asserted that there was a very high risk of the appellant reoffending and of him causing serious harm to the public, and the detention order in a YOI was made.

Within 3 months of sentence Stead was transferred to a psychiatric institution - St Lukes, Ebbw Vale - and that is where he was held when the appeal was heard. So he must have been subject to a s.47 transfer order, possibly with a s.49 restriction order. Counsel for the appellant asked the Court of Appeal for a s.45A order, and this was made, presumably in ignorance of the transfer order already in place, with the CA being desirous of ensuring his continued treatment in a clinical setting.

Ultimately, the error was brought back to the Registrar's attention, ${ }^{25}$ possibly as a result of a new solicitor becoming involved in the case, but by that stage the Court of Appeal was functus officio. The registrar directed them to the Criminal Cases Review Commission and they in turn referred the matter back to the Court of Appeal.

The issue of clinical need trumping protective or punitive justifications is interesting. And one might argue that the courts are understandably privileging therapeutic endeavours in these cases involving young offenders, whilst asserting,

25 This episode had the potential for an interesting ethical dilemma, but in the event the view was simple that the error had to be put right. 
as they did in Ruby, that 'clinical advantage 'is not the test as to whether s37/41 is the appropriate disposal' (see $\mathrm{R} v$ Ruby at para 36).

In Ruby it was the Broadmoor assessing psychiatrist who suggested the s.45A to the trial court. Ruby was given an IPP for three offences of wounding with intent, together with the s.45A. In Fort the trial judge went against the unanimous psychiatric evidence which favoured hospital management and a s.37/41, and ordered custody for life with a four year minimum tariff (although the trial judge got the terminology wrong). Subsequently, the offender was brought back to court so that the judge could make a s.45A order to ensure his placement in a clinical setting rather than a YOI. It was only on appeal, where counsel was still seeking the s.37/41 that the Court of Appeal quashed the s.45A as unlawful and imposed the $s .37 / 41$.

\section{Wrong IN PRINCIPLE}

There are three cases which fall into the 'wrong in principle' category - the $A G$ Reference case, Fort and Ruby; and one below, House, which could be treated as either wrong in principle or as manifestly excessive.

The $A G$ reference case is one where the CA replaced a s.37/41 with an IPP and an advance transfer order. And in Fort an IPP was replaced with a s.37/41. Both offenders were under 21 and the Court discussed the difficulties this raised with s.45A (which was deemed to have been appropriate had the offenders been 21). The two cases are arguably mirror images of one another.

The $A G$ reference case involved unlawful act manslaughter in the course of a drug offence; Fort, manslaughter by diminished responsibility of his mother. In the $A G$ reference case the s.37/41 appeared to be partly prompted by a desire to avoid a treatment hiatus in prison; but as the CA observed, this could have been avoided through the use of an IPP with an advance treatment order under s.47, so the defendant could still have gone direct to Broadmoor after conviction (which was where he had been held on remand having developed paranoid psychosis). In both cases future risk was key, but in the $A G$ reference case that risk arose in part from his pre-existing criminal lifestyle, which might be resumed even after successful treatment. In Fort, who had no previous convictions and whose offence appeared senseless, the risk of further serious offending was deemed not significant once his mental disorder had been cured or substantially alleviated.

The reasoning in the $A G$ Reference case was dominated by a discussion of future risk and recall arrangements, where the s.37/41 order was considered second best as a means of managing risk following release, compared with Parole Board release following a sentence of imprisonment. Thus in para 17:

[t]here is an absolutely crucial difference between the two forms of regime. Under an order for detention for public protection release is dependent upon the responsible authority being satisfied that the defendant is no longer a danger to the public for any reason and principally not at risk of relapsing 
into dangerous crime. Under the hospital order regime release is dependent upon the responsible authority being satisfied that the defendant no longer presents any danger which arises from his medical condition. Similarly, and critically, release under the detention for public protection regime is on licence and the licence can be revoked if the defendant shows that he remains a danger to the public from crime. It is possible and indeed inevitable that the licence conditions will be designed, among other things, to prevent association with dangerous criminals. Under the hospital order regime, recall is available but only if the defendant's medical condition relapses. Simple crime does not trigger a recall under the hospital order regime.

The Court of Appeal was critically concerned about the risk that the offender might resume, after release, a criminal lifestyle and wanted to retain the power to recall him: as they said (para 19), '[W]e hope it will not, but the power simply has to be there'. In cases of homicide, even unlawful act manslaughter, the concern about a need to be able to recall is pressing, even if not fully understandable. An indefinite power of recall is only associated with a life sentence, so at some point for all other offenders the power to recall will cease to exist. Are mentally disordered offenders simply perceived as so much more unpredictable that such a power needs to be engineered, even where their offending may be unrelated to their disorder?

Discussion arose about what was the disposal most likely to ensure the defendant's recovery (and hence future public protection) and that if he were to be returned to prison this might foster the anti-social aspects of his behaviour attributable to the conduct disorder. Yet the court notably remarked:

But in the last resort if there exists a tension between the risk which $\mathrm{Mr}$ Ryder has identified on the one hand and a complete absence of control on licence on the other, we fear that the risk has to be taken in order to achieve the licence control. (para 20)

Again, control over the risk of future offending takes precedence over the risk that anti-social conduct might be fostered by the return to prison, which ensuring longer term control entailed. Even when the Court accepted that there may be a greater intensity of management under hospital release, they argued that 'intensity of supervision is no substitute for the test of release and the test for recall to which the supervision has to be directed'. (para 20)

And the Court perceptively noted that even if he were to be psychiatrically recalled on the basis of a possible deterioration in his mental disorder evidenced by his offending, if on examination in hospital there was no sufficient evidence of 
medical relapse they could not keep him. ${ }^{26}$ The Court then substituted an IPP with a six year tariff, plus a s.47 advance transfer order for the existing s.37/41, to ensure that he stayed in the therapeutic regime in which he was then held.

As noted above, in Fort the CA concluded that the sentencing judge should have imposed a s.37/41 and not an IPP since it was held that if the defendant's mental disorder were successfully treated or alleviated he would not pose a significant risk to the public of committing further serious offences. And his mental disorder, by the time the case reached the Court of Appeal, was recognised to be both severe and associated with violence when he was not clinically managed.

Prior to killing his mother, Fort had no previous convictions. The offence appeared senseless; he could not explain it, and he called the emergency services himself. He had no previous psychiatric history although he had had intrusive thoughts of a violent and sexual nature. A number of diagnoses were canvassed, which could have resulted in his grossly dissociated state at the time of the killing, although it was agreed at trial that he suffered from a schizoid personality disorder.

Whilst agreeing with counsel's notion that it would be 'utterly wrong' to send Fort to prison, the judge, with regret and hesitation, sentenced him to custody for life on the grounds that it was his 'duty to protect the public' and that that was 'only achieved by imposing a sentence that means his release is on the direction of the Parole Board which has in mind, and only in mind, the protection of the public' (para 35). Risk avoidance was paramount.

The judge's sense of 'I have no alternative but to....' was, as is often the case, wrong. The Court of Appeal took the view that a s37/41 order, as the doctors had recommended, was the right course of action. Why did they take a different view?

First, by the time of the appeal Fort had a diagnosis of schizophrenia and was responding to medication. Second, the medical evidence was clear that his violence was directly linked to his mental disorder: as Dr Maganty noted:

[t]hought insertion involving violent thoughts being inserted into his mind together with in some instances passivity (his actions being controlled by an external force). These symptoms have consistently been worsened by stress, such as examinations prior to the index offence, moving prisons in a custodial setting, withdrawal of CDs in a custodial setting and subsequently in a hospital setting (which he uses to distract himself from his thoughts). (para 41)

Before any discharge could be considered he would require testing over a number of years in stressful situations and a clear plan to prevent relapse in the community. And returning to prison would mean exposure to stress, which could

${ }^{26} \mathrm{R}$ (on the application of MM) v SS for the Home Department [2007] EWCA Civ 687. 
not be controlled, posing a risk to officers, inmates, healthcare staff and himself of serious harm, whilst likely undoing the therapeutic work already undertaken.

Since the risk of offending derived from the disorder, and discharge would not occur all the time there were symptoms of the disorder, then there would be no discharge which posed risk. Now that the link was clear, and there was no evidence of personality disorder, release could be managed from a hospital setting.

Third, the Court of Appeal was clear that diminished responsibility manslaughter required an assessment of the seriousness of the offence, by reference to the offender's culpability and the harm consequent upon his actions (s143 of the CJA 2003). ${ }^{27}$ Imprisonment for life was not precluded in particularly grave cases where the defendant's responsibility remained high, but where the defendant, on the basis of all the medical evidence, did not have much, if any, mental responsibility for his actions in killing his mother then s.37/41 may be appropriate. The choice between this, and life imprisonment with a minimum term or an IPP, was critical, and the differences crucial. Reference was made again to the analysis in the Attorney General's Reference case above. If a significant risk of serious harm remained, even if the mental disorder were cured or substantially alleviated, then the sentence should focus on that residual risk (para 61). Yet, the Court of Appeal decided that the trial judge was wrong to conclude that Fort could still be released when a danger under s.37/41. In so doing they tactfully concluded that the trial judge did not misunderstand the law, he just arrived at a different evaluation of the evidence; which was perhaps understandable since the medical evidence had not dealt fully or clearly with the issues at trial with regard to causation or residual risk. But that the judge's conclusion was wrong in the light of the full evidence now available:

[w]e are satisfied that this appellant would not continue to pose a significant risk of serious harm to members of the public occasioned by the commission of serious offences once his mental disorder, in all its three manifestations, has been cured or substantially alleviated such as to enable him to be discharged (albeit conditionally) from a section 37/41 order. (para 73, emphasis in original)

Ruby has a complicated psychiatric and legal history, and like, Fort above, the Court of Appeal were very reluctant to criticise the trial judge given that the intervening time had permitted new understandings to emerge of the offender's condition. In Ruby it was many years before his case came back to the Court of Appeal, during which time there had been further incidents of violence directed at other inmates, patients and staff; and he had attracted a further IPP sentence and a further s.45A order. He was not obviously an offender-patient with whom it

27 Para 53. See R v Kehoe (Bridie Joanna) [2009] 1 Cr App R (S) 9; R v Clive Wood [2009] 1 Cr App R (S) 2; and $\mathrm{R} v$ Welsh [2011] 2 Cr App R (S) 68. 
was easy to sympathise. His time at Broadmoor was peppered with manipulative incidents of violence where he seemingly attempted to be returned to prison. But whilst there was diagnostic disagreement about the role of anti-social personality disorder in his autism, there was clinical agreement that his offending derived from his disorder.

The question the Court of Appeal addressed was whether he should be on a s.47/49 transfer order from his IPP or on a s37/41 hospital order with restrictions? The Court asked itself what would the original sentencing court have done if the judge knew then that the s.45A order could not be made (as he was under 21). This is arguably an inappropriate question since in order to arrive at a $\mathrm{s} .45 \mathrm{~A}$ order the court has to have already dismissed the possibility of a s.37/41. So again we have evidence of the tail of s.45A wagging the dog of sentencing. It had been an outcome driven disposal - detention in a therapeutic environment - with a backstop of prison if the personality disorder, together with the autism spectrum disorder, proved problematic to treat.

The Court of Appeal noted that:

We emphasise that clinical advantage is not the test as to whether the appropriate sentence is detention or disposal under section 37, or at least the critical test. The test is that identified by the Vice President in the Attorney General's Reference case. (para 36)

Namely, the extent to which risk exists independently of disorder in order to ensure that the appropriate test for release is applied by the appropriate body. In quashing the sentences and imposing a s.37/41 the Court of Appeal stated:

We should therefore now re-sentence the applicant. We must do so on the basis of the information available to us. If we took the view that there remained a significant risk the applicant might be released while he was a danger to the public, we would leave the indeterminate sentence undisturbed and rely upon the Secretary of State to exercise his power under section 47 of the Mental Health Act 1983 to transfer the applicant to hospital. We are, however, satisfied upon the written evidence of two properly certified medical practitioners, Dr Carpenter and Dr Edwards, that the applicant should be detained at Mackaness Ward, Saint Andrews Healthcare Northampton [...] (para 38).

Thus the assessment of risk was being very closely associated by the Court of Appeal with the psychiatrists who gave evidence.

Again, it was the perceived causative link between the disorder and violence that made the MHA disposal the appropriate one, and not prison with the s.47/49 transfer. And it is further interesting to note that one of the clinicians asserted that the Parole Board would struggle to assess risk in someone with Asperger's/autism spectrum disorder and personality disorder, at least raising the 
possibility in the Court of Appeal's view that the MHT or the Secretary of State was better placed to assess future risk on the basis of clinical advice from those treating Ruby.

\section{MANIFESTLY EXCESSIVE}

There is only one case, House, that could be characterised as a 'manifestly excessive' sentence; but even the Court of Appeal does not use these words so it might as aptly be described as wrong in principle. The trial judge gave a sentence of life without a tariff together with the s.45A; the Court of Appeal imposed a tariff of nine years, arguing that this was not such an exceptional case that a tariff should not have been imposed.

Two aspects of the case are interesting. First, the appeal occurred after 19 months, by which time House had been returned to prison, his paranoid schizophrenia having responded well to treatment. Even so, he was held mainly in the prison hospital wing. Second, although his co-occurring anti-social personality disorder persisted it was clear that, as a life sentence prisoner, he was not a priority for transfer back to hospital for further psychiatric rehabilitation prior to release. In all likelihood he would only be considered for transfer once he had reached his tariff date. The disadvantages of leaving the therapeutic track with respect to continuity of rehabilitation into the community are clear.

\section{CASES UPHELD}

In five cases involving s.45A orders, Staines, Cooper, Fox, Jenkin and Poole, the Court of Appeal upheld the trial judge's decision to order a sentence of imprisonment. In all these cases the management of future risk is key, together with assessments of partial culpability. Poole is an unusual case, in that it involved offences of dishonesty, and is discussed separately below. The other four cases all involved offences of the most horrific nature; in Fox these were described as 'the stuff of nightmares'. Staines is an early example of an offender with psychopathic disorder who was given a discretionary life sentence and a s.45A order. And it is also a case where the Court is critical that s.45A was not then available in cases of mental illness alone. Cooper is referred to as the authority for an analysis of the origins, purpose and effects of s.45A. Ironically, it largely reproduces the sections from the White Paper cited by the House of Lords in Drew [2003] but not only gets the date wrong, placing the White Paper in 1999, but also inappropriately places an emphasis on partial culpability as being the key to the use of s.45A. Finally, an emphasis on previous offending, for example in Fox, or on previous violence in Jenkin, is noted alongside the assessment that criminal culpability was not wholly extinguished in the current offence and that the sentence of imprisonment could not therefore be wrong in principle. 


\section{(i) The issue of partial culpability}

This argument needs to be tackled head on. First, because it is evident from the cases discussed above that residual criminal culpability could still be found alongside the CA's conclusion that a sentence of imprisonment was wrong in principle. And second because where a conviction has occurred there will always be some element of criminal culpability. Criminal culpability is only extinguished in the ngri cases. The issue is to determine how much culpability there is on what is clearly a sliding scale. And that sliding scale is a moving feast, to mix metaphors. Arguably, the problematic cases are those where the disorder is thought to cause the offending, but that ngri is not the verdict (perhaps because its narrowness makes it inapplicable, or because it was not pursued when it might have been). And the situation can be further confused where the court accepts pleas which entail intent on the part of the accused, or the jury finds charges made out, which necessarily entail an element of intent, as occurred in Fox, despite medical evidence that he was unlikely, due to his psychotic state, to have formed the requisite intent. This verdict in Fox weighed heavily with the judge at sentence in his consideration of partial culpability.

Thus, the courts may be faced both with divergent views about the accused's culpability and with clinicians saying if this offender is treated there will be no or only minimal risk of reoffending. In that sense, future risk may be extinguished, albeit the courts have found a measure of current culpability (even if wrongly, depending on how robust a view one takes of a determinative relationship between disorder and offending: see Peay 2011, or of the jury's rejection of medical evidence, where the judge has permitted them to reach a verdict).

A short detour into the case of $W$ ood is required. ${ }^{28}$ Wood involved diminished responsibility manslaughter (a killing following a homosexual advance) where counsel described Wood's culpability as being reduced by the 'substantial diminution in his responsibility' (para 13). The Court of Appeal disagreed saying that 'a very substantial element of mental responsibility remained' (para 19). They observed that in diminished responsibility manslaughter cases culpability 'may sometimes be reduced almost to extinction, while in others it remains very high' (para 21). In Wood's case they felt his responsibility was just 'but only just sufficiently diminished for the purposes of s.2 of the Homicide Act' (para 19). Thus Wood fell at the top end - there was a prolonged murderous attack, and his actions before the killing and his insight after it, in terms of what could be done to cover up the killing and his involvement in it, all pointed to a very high level of culpability. This was contrasted with Kehoe which was held to be at the lowest level of seriousness:29 an alcoholic woman had killed another alcoholic in the context of provocation (an assertion by the deceased that the accused had encouraged a sexual assault on herself by a third party some months earlier) and mental disorder. Kehoe had a background marked by emotional, physical and

28 See footnote 27 above.

${ }^{29} \mathrm{R} v$ Kehoe [2009] 1 Cr App R(S) 9. 
sexual abuse, but there was also a significant criminal history. The assault had been extended so one can only assume it was the context of provocation and alcohol which reduced the level of seriousness. One might argue that $W o o d$ and Kehoe are not so very far separated, but the Court of Appeal clearly did think they lay at opposite ends of a continuum of responsibility.

The Court of Appeal in $W$ ood also made reference to the schedule 21 factors under the Criminal Justice Act 2003 for fixing sentence length when sentencing those convicted of murder. These factors about a homicide also went to establishing its seriousness, aside from the reduction attributable to diminished responsibility. This seems to imply that even once the diminution of responsibility is calculated it can then be enhanced or reduced by other factors. This is a very slippery slope of a sliding scale.

A court's assessment of residual culpability might accordingly be expected to be influenced by a series of ineffable considerations, undoubtedly prone to human interpretation. In Staines, her withdrawal of admission of command hallucinations was dealt with in the context of partial culpability, rather than as evidence of a disordered state of mind at the time of her interviews. In Fox, where the offender gave way to command hallucinations, this was identified as evidence of his control and choice, and thus the retention of culpability. As the court observed, where the offender bears substantial responsibility for the offending, public confidence required the passing of a life sentence rather than a restriction order. ${ }^{30}$ In Jenkin, the CA pointed to his behaviour before and after the offence (gouging out his girlfriend's eyes) to justify his life sentence with a six year tariff and a s.45A order. They cited with approval the judge's remarks noting that Jenkin, who had a history of violence, bore a significant responsibility for what happened despite his mental disorder. And that responsibility lay in part with his prior drink and drug taking, and in part his behaviour after the offence when his reaction when questioned about the crime afterwards was not to suggest that he was driven to commit it, or that Miss Nash was the source of any threat to him - a belief which could be explained by delusions - but to minimise and excuse his own actions. (para 26)

The issue of partial culpability was also examined in considerable detail in Cooper. Cooper had killed the mother of his child and then attempted to murder his step-father. The two offences were separated only by a brief car drive, and it was accepted that the offences would not have occurred but for his acute psychotic delusional state. But for the former offence his responsibility was held significantly diminished due to his acute psychotic breakdown; yet for the latter he retained significant culpability, with the offence being characterised more as an act of revenge than deluded and misconceived self-defence (as was the former). As the Court of Appeal's concluding remarks revealed, they felt there was no basis for interfering with the trial judge's conclusions. Moreover, the Court made

${ }^{30} \mathrm{R} v$ Welsh [2011] EWCA Crim 73. 
reference to his voluntarily ingesting drugs which had led to his illness (in that he was suffering from the effects of withdrawal at the time of the offences) for which he bore some responsibility. Does this look like the Court of Appeal casting around for a basis to attribute responsibility in the context of what was clearly an acute psychotic episode, however brought about?

What would have been the outcome had this case not been argued on the tricky basis of partial or non-responsibility (the latter clearly not being consistent with the defendant's pleas), but on the issue of why the s.37/41 must have been rejected in the first instance by the sentencing judge, before he ever arrived at a consideration of the IPP plus the s.45A? What made s.45A the most effective way of dealing with the offender?

Fox illustrates well the differing approaches of the clinicians and the courts. The former favoured a s.37/41 on the basis that the offending occurred in the context of an acute psychotic breakdown; the courts focussed on partial culpability and identified both the formation of an intention to cause grievous bodily harm; and that Fox had effected an escape from the scene. Arguments about being in thrall to his command hallucinations were seemingly weighed in the context of evidence that he exercised control over his behaviour in other ways, including the use of alcohol before the offence, which would have made resisting the command hallucination more difficult. Indeed, even those command hallucinations included good voices telling him to resist and bad voices telling him to do harm. How meaningfully discernible all of this is must be questionable; moreover, just how much his culpability was reduced by his disorder and just how much allowance should be made for that in the calculation of his prison term can hardly be weighed to a nicety.

Finally, it is worth noting from Fox that the Court of Appeal expressed its usual reluctance to interfere with the findings of the trial judge of Fox's dangerousness under the Criminal Justice Act 2003 (CJA). Yet they also noted that the sentencing judge had not used the term that he bore 'a significant degree of responsibility' for his offences. But this was not to be determinative in the context of his sentencing remarks as a whole. Rather, the Court of Appeal seems to argue the issue backwards by saying that because the trial judge gave a s.45A with a substantial ingredient of custody he must have found a significant degree of responsibility.

\section{(ii) The management of future risk}

In Staines it is a further irony that the clinical view was that her disorder, by the time of the appeal, would prove treatable over the long-term. This in turn raised further concerns about the prospect of release if she were subject to a s.37/41 rather than the discretionary life sentence. The view of the sentencing judge, whilst tempered by the knowledge that she would go to hospital in the first instance via the s.45A, was that she should ultimately stay in prison 'until such time as it is considered safe to allow you back into the community'. The Court of Appeal shared this anxiety about the management of future risk. It emerged in 
two ways. First, their acceptance that the s.45A order provided a 'safety-net' (para 27 ) in the event of non-treatability but continuing risk; and secondly, that the method of release from the s.45A - namely by the Parole Board - would focus on the risk the prisoner posed, rather than on their medical detainability under the MHA, which would be the focus for tribunal release. As noted above, the Parole Board is under a duty to release, once an offender has passed his or her tariff date, where they are satisfied that it is 'no longer necessary for the protection of the public that the prisoner should be confined' (s.28 (6)(b) Crime (Sentences) Act 1997). ${ }^{31}$

In so doing the Court of Appeal noted the observations of Dr Noon:

The primacy of risk as the basis on which a life sentence prisoner is managed is well illustrated with regards to substance misuse in the community. Whilst on life licence, continued abuse of alcohol or illicit drugs could, in themselves, be sufficient grounds for recall due to their effect on risk. With a restriction order such abuse would have to result in deterioration in mental disorder, or as a minimum a likelihood of deterioration, before recall to hospital would be deemed appropriate. This could have a marked difference in the risk the general public are exposed to, as under a restriction order risk must be related to the patient's mental disorder. (para 22)

Of course, both these assertions can be contested: patients can be detained on s.37/41 in the presence of minimal disorder where risk persists (see above at footnote 20) and patients have been recalled for abusing drugs in advance of any recognisable signs of mental deterioration. ${ }^{32}$ But once made, these assertions were to reappear in the thinking of the Court of Appeal in subsequent cases, for example in Cooper (para 20). The risk to the public was simply perceived to be greater on a s.37/41 order than on a life sentence of imprisonment; and that risk could persist 'for an indefinite time into the future' (trial judge in Cooper). Ironically, in Cooper (para 20), the Court of Appeal asserted that recall for those discharged by the Mental Health Tribunal could take place as a result of failure to comply with a support package of care. This is itself doubtful.

In Fox the medical evidence unanimously supported a s.37/41 following horrific offending which occurred in the context of an undiagnosed acute psychotic episode in the course of paranoid schizophrenia. However, he did have a history of seemingly unrelated violent offending; so future risk was an important factor even if his disorder were dealt with. Of course, the extent to which one sentences mentally ordered offenders on the basis of future risk rather than past offending is problematic, albeit s.142(1)(b) of the CJA 2003 asserts that the reduction of crime is one of the purposes of sentencing to which a judge must

31 See footnote 22 above.

32 See footnote 26 above. 
have regard. But future risk undoubtedly figures prominently in the way in which mentally disordered offenders are dealt with by the courts.

Given that the Court of Appeal goes against the medical evidence they do underline that this is a decision for the judge and that a restriction order can be imposed against the wishes of the clinicians ${ }^{33}$ or the judge can reject the unanimous view that one should be imposed. Whether the Court is comfortable about this is not clear, but they also refer to two other issues. First they assert, given that Fox has both the life sentence and a s.45A, that the subsequent combined availability of review by both the MHT and the Parole Board to deal with changes in circumstances subsequent to sentencing provides adequate safeguard to the offender, without the need to entertain appeals to the Court of Appeal long after the conclusion of the sentencing process. And that those bodies are better equipped than the court to have regard to the medical considerations attending an individual offender and, importantly, 'the extent to which the offender would, if released, present a continuing source of danger to the public and what, if any, measures can properly be imposed to eliminate, control or monitor as the case may be such risk of danger as remains' (para 20 - note para numbers wrong in official transcript). Second, they observe, somewhat curiously, that whilst release on life licence may not have the comprehensive package of social psychiatric support and reporting requirements imposed by a MHT, there was no reason why the Parole Board should not make appropriate arrangements. Is this an attempt to suggest that life licence arrangements can be bolstered to match those pertaining to conditional discharge? If so, it is a reversal of the usual reasoning which points instead to the superior basis for recall of those on life licence.

This may, of course, simply have been a somewhat innovative Court of Appeal. For it is interesting that they also suggest (again in conflict with previous approaches) that for a patient to persuade a tribunal that his mental illness was sufficiently abated for his continued detention to be no longer justified, he would need to demonstrate that he did not pose a risk to the public.

One other intriguing issue arises which applies in Jenkin, and indeed in any case where a life sentence is given alongside a s.45A; namely, why the s.45A order was felt necessary at all? Jenkin could as easily have been subject to a s.47/49 transfer to hospital alongside the life sentence, which would have achieved the same effect with respect to his long term risk. Perhaps it is simply easier for the courts to impose a s.45A order, which is under their discretion, rather than apply to the Ministry of Justice for an advance transfer order at the point of sentence. And one might argue that once a piece of legislation is in place, it will be used. Even if the same effect could have been achieved without it.

${ }^{33} \mathrm{R} v$ Royce (1981) 3 Crim LR 58. 


\section{(iii) $\quad \mathrm{R} v$ Poole [2014]: conflicting objectives}

Poole does not sit readily with the other appealed cases. Poole, an offender with a long history of offences of dishonesty and some minor violence, was already detained on a s.37 hospital order when he was convicted of conspiracy to steal from fellow patients. The Court of Appeal quashed his victim surcharge order on a technical issue of construction but upheld the judge's s.45A order with a sentence of imprisonment of 18 months. Everyone agreed that he was likely to serve the whole of this sentence in hospital, when he would then revert to a s.37 order.

Initially the judge had imposed a s.45A order without a limitation direction, reflecting the evidence that he was not thought to pose a risk of serious harm. The case had to be brought back to court two days later under the slip rule for the limitation direction to be added since s.45A orders cannot be made without the limitation direction. This is another area of confusion about the orders, but the Home Office Circular (52/1997) in paragraph 7 makes clear that the one should not be made without the other. The reasons stated there are that '[T]his is to facilitate the transfer to prison of any defendant who has either met all treatment criteria or has failed to engage with them'. Clearly, administrative convenience was at the forefront here. In contrast, the psychiatrist recommending the s.45A order wanted it to ensure that if the therapeutic alliance broke down and treatment became impracticable then Poole could be transferred to prison. The Court of Appeal argued that there was an element of culpability which required punishment: his culpability was not so diminished as to call for treatment rather than punishment. The identified risk element, such as it was, was a risk of financial harm to the public were he to engage in further offences of dishonesty. So three different objectives underpinned the order.

However, what is interesting is why the sentencing court did not pursue the recommendation of the other psychiatrist that a suspended sentence of imprisonment be imposed. Such a sentence would have reflected his partial culpability, and presumably any further offending during the currency of the order would have allowed him to be resentenced as necessary. Yet the court went with the s.45A order, even though the reality was that he was going to stay exactly where he was, in hospital, since his behaviour, the nature of which is classically associated with personality disorder with emotional and dissocial features, was not manageable in a prison or community setting. Presumably, the court simply framed the case as one falling within the MHA rather than the CJA 2003.

Poole also illustrates that s.45A orders, since they do not require a risk of serious harm to be present before they can be made, are equally viable at the bottom as the top end of the spectrum of seriousness. To date, they have been primarily used at the top end: but the potential for their expansion is clear. 


\section{(iv) Residual issues}

A number of other issues arise en passant in the CA's deliberations in these s.45A cases. And they demonstrate a somewhat ambiguous approach to this group of offenders. There clearly is a more pronounced emotional component with respect to the younger offenders, and something not wholly divorced from this for other offenders where their offences have so clearly occurred whilst they were in the grip of illness or there was a recognition that many had longstanding difficulties in their lives which may have underpinned their current state: for example, Paula Staines's life story was described by the CA as one of 'unmitigated and profound tragedy'. Yet it is also hard for the CA not to be ever aware of the carnage these offenders had wreaked in the lives of others.

However, offender patients are also perceived as manipulative (perhaps understandable given the hinterland of s.45A in the area of psychopathic disorder, and the associated ruthlessness and mental capacity of many of the offenders) and not just as being difficult to engage in therapy; they could also be perceived as trying to engineer a transfer to prison or to secure a discharge. S.45A was seen as both playing a helpful role here (by preventing unjustified discharge) and alternatively as potentially impeding treatment (where clinicians viewed the orders as enabling patients to avoid treatment by striving to secure a return to prison). Other clinicians saw the problems as lying in the fear that could be engendered in patients where they foresaw the possibility of a return to prison where treatment was successful. And then there was the problem of those who became treatment resistant, and were switched to clozapine, which required very careful medical monitoring. The issue of relapse in a non-clinical environment, with a medical disposal at the end, also worried the clinicians. In many respects, the s.45A raised as many problems as it solved, depending on the perspective from which one viewed the offender-patient and future risk. But concepts of the s.45A as a 'safety-net' abounded in the cases.

\section{OTHER CASES WHERE S.45A WAS RAISED.}

Two other CA cases are worthy of brief mention. In Imtiaz Abmed ${ }^{34}$ the Court of Appeal refused to use a s.45A as a way of solving the dilemma that illegal immigrants posed where after-care in the community on a s.37/41 would be highly problematic. They refused to countenance this as a way of ensuring that he would be returned to prison when fit to be discharged: perhaps the Court thought this was a flexible use of s.45A which went far too far. In any event, they characterized Abmed as somebody who was ill who required treatment: he was not a criminal who required punishment. And in Anderson ${ }^{35}$ the clinical evidence raised the potential use of a s.45A as a way of preventing bed-blocking, but again the Court was content to permit the offender to continue on his simultaneous

\footnotetext{
${ }^{34} \mathrm{R} v$ Imtiaz. Ahmed [2012] EWCA Crim 99.

${ }_{35} \mathrm{R} v$ Anderson (Darren Gabriel) (2013) EWCA Crim 2212.
} 
IPP and s.37/41. The case had a complicated history involving more than one offence and the sacking of Anderson's legal team, attributable to his disorder, which prevented the appropriate reports being before the sentencing court. Dr Somekh, in favouring the s.37/41 approach, argued that any post release relapse into criminality (and release was a long time away) would lead to recall. He said the distinction between relapse to criminality and mental relapse was a false distinction. In so doing, he was at odds with the prevailing view in the Court of Appeal. Again, safety-first triumphed and the IPP was left in place.

Finally, there are three recent cases from the popular press, Karl Addo, John Ward, and Michael Herrington. ${ }^{36}$ All were diminished responsibility manslaughter cases and all received life sentences with a s.45A order, despite the varying degree to which their offences were attributable to their mental disorder.

\section{$R$ V CLARENCE: THE EXCEPTIONALISM OF SINGLE CASES?37}

Tania Clarence pleaded guilty to manslaughter on grounds of diminished responsibility with respect to killing her three disabled children. That sentence alone should be sufficient to make any reader wary of what general relevance this case might have. However, there are some pertinent issues. Although we only have the judge's sentencing remarks they are detailed and the disposal, a s.37 hospital order, is one with which almost everybody would agree. ${ }^{38}$ However, there is scope to reflect on the markedly different treatment of this case, by comparison with the s.45A cases above. Given that much has been made above of the context of decisions, it should be noted from the outset that Clarence smothered her infant children in their beds. There was none of the bloody carnage wreaked when adults are assaulted or killed using knives or blunt instruments. And the nature of her disorder sets her apart from the bulk of the s.45A cases.

Clarence suffered from recurrent depression. She attempted suicide after the homicides. The clinical evidence was clear and agreed: namely, that the offences would not have occurred but for the mental disorder. And it was summarised in stark terms by the judge: 'What you did was a product of your mental illness'. The judge accepted that because of her severe mental illness she perceived she had no option but to kill the children and commit suicide. Moreover, she remained 'vulnerable to a significant deterioration in (her) mental health with the concomitant risk of a return to suicidal thoughts' and that she would need 'further treatment involving both close psychiatric supervision and regular psychological therapy [...] for the foreseeable future'.

The judge concluded that she was not dangerous under the CJA 2003 so there would be no indeterminate sentence or extended sentence. And he asserted

\footnotetext{
36 Given Table 2 above, they are likely to be the preponderance of recent s.45A orders.

37 See http://www.judiciary.gov.uk/wp-content/uploads/2014/11/r-v-clarence-sentencing-remarks.pdf.

${ }^{38}$ It must be highly unlikely that there would be any prosecution appeal in this case, so the sentencing remarks will remain the best analysis of the case.
} 
that she did not qualify for s.41 or s.45A orders. There was no mention of any potential future risk to the couple's fourth child were her illness to recur; and in turn presumably no need for any explicit recall mechanism. A s.37 hospital order would suffice. Thus, the judge described his choice as a stark one between a determinate prison sentence or a hospital order.

At one level this looks like an open and shut case of the disorder extinguishing any responsibility for the offending. But that cannot be the case as the plea entails an acceptance of an intention to kill (and clearly ngri was not possible here as Clarence knew what she was doing, and knew that it was wrong). At best, and on this the judge and the prosecution agreed, her culpability was low, albeit not completely extinguished.

However, the issues of responsibility and culpability were separately raised. The judge observed that it was 'for the prosecution to make me sure, on the evidence, of the assertions that they make as to your responsibility and culpability'. Putting aside the implication that hospital rather than prison was the default position, ${ }^{39}$ there was a clear difference between the prosecution and the judge on the issue of responsibility. The judge concluded that the latter was also low, with the prosecution asserting, despite their acceptance of the plea, that her responsibility 'still remains considerable, such that a prison sentence ought to be imposed - albeit that the medical evidence shows that a prison sentence would lead to a deterioration of your mental illness'. This would be consistent with the cases above where clinical advantage was not determinative (Ruby): rather it was whether risk existed independently of disorder so as to ensure the proper test for release was applied by the appropriate body. However, risk had been dismissed as a pertinent issue in Clarence. So the prosecution must have been advocating prison on the basis of partial culpability/responsibility.

Whether the terms 'responsibility' and 'culpability' are being used in the same fashion here as in other contexts is arguable; for example, the Sentencing Council uses culpability, covering such facts as premeditation and the targeting of vulnerable victims, together with harm caused or intended, to gauge the seriousness of offending. Common sense would say that Clarence was responsible for her children's deaths, albeit there were some tangential issues about the heavyhanded presence of over 60 professionals visiting the family to support them, and no mention of the role of the husband who had been absent for 10 days before the killings on a golf holiday abroad and who had then again left immediately with their non-disabled daughter for a visit to South Africa, leaving Clarence in charge of the children. But the court was clear that to the extent there was any planning 'it was clearly the product of your mental illness not any culpable conduct over and above that illness'. And here failure to get treatment for her mental illness was not culpable either - but rather due in part to that mental illness. This also contrasts markedly with those offenders whose prior fault in taking drink or drugs or withdrawing from medication has all been held to contribute to their prior

39 Arguably correctly following Birch. 
culpability. The objective abuse of her position of trust was also attributed to the mental illness. And finally, she was judged on the basis of her honestly held beliefs about the impact of the actions of the professionals and her perception that the situation could only get worse. 40

So, mental disorder is doing an awful lot of causal work here. And despite the fact that the disorder pre-existed the killings, albeit it was described as a major depressive episode, and others had recognised she was under immense stress, she had apparently managed to minimise her symptoms and the children were described as happy and well looked after. It was apparently only once she was alone with the children that her ability to form a rational judgment was substantially impaired: indeed, so substantially impaired as to explain why she killed them.

Why was she not considered dangerous? First, there were no previous convictions, so no criminality unrelated to disorder. Second, future danger was cast solely in terms of to her own heath. And there was no mention of what might happen were the disorder to recur after release, or to any future risk to her fourth child. This is on a par with Birch where a hospital order was considered sufficient in the context of diminished responsibility manslaughter where depression, alcohol and high degree of planning collided. Third, there was a chronology to the killings, and yet the mental disorder covered them all equally: again, this was in contrast to Cooper above. Fourth, and as mentioned above, whilst the violence was strongly related to the disorder, it was the violence needed to kill disabled children, not able bodied adults.

Whilst tangential reference was made to schedule 21 of the CJA 2003, there was no explicit mention of the 30 year starting point which would have been appropriate, even without substantial planning or premeditation, had she been convicted of murder.

The judge said he had no hesitation in concluding that her responsibility and culpability were low: in making a hospital order under s.37 MHA without restriction, he observed that she would not be released until she had recovered from her illness. Had this approach been adopted in some of the s.45A cases would their outcomes have been different? Is this the resulting contrast between a stereotypically gendered crime and crimes blinded by violence?

\section{Partial CUlPability AND CAUSATION IN $R$ V CLARENCE}

The focus on causation is pertinent. First, because the newly drawn defence of diminished responsibility under s.2 Homicide Act 1957 requires both that there was a substantial impairment of her ability, in this case to form a rational judgment, and that this was the explanation for her carrying out the killings (Mackay 2010).

40 An approach which is commendable consistent with Article 14 of the UNCRPD. 
'Diminished responsibility' per se in the defence of diminished responsibility has gone.

Second, that she could exercise self-control when ill is irrelevant as it is sufficient under new diminished responsibility for any one of three cognitive areas (understand, form a rational judgment, exercise self control) to be substantially impaired. ${ }^{41}$ Assessing whether a defendant has the ability to act in a manner that justifies the attribution of criminal responsibility has long troubled the courts. Thus, there is no scientific measurement of the degree of difficulty which an abnormal person finds in controlling his impulses ${ }^{42}$ and more recently there is no simple scientific test of whether a defendant's 'mental responsibility for his acts and omissions in doing or being a party to the killing' is 'substantially impaired'. ${ }^{43}$

Yet in Clarence the clinicians' conclusions about the link between the disorder and the offending were accepted without equivocation. This may be a rare open and shut case. But in a number of the s.45A cases such conclusions were also drawn by the clinicians; and yet a s.45A order resulted. And it is somewhat out of keeping with the more nuanced literature on the relationship between violence and mental disorder. Clearly, there are individual cases where the link is undisputed; but the literature is more hesitant about the generality of the link (Peterson et al 2014; Skeem et al 2011). And Buchanan and Zonana (2009) argue powerfully that psychiatrists ought only to offer possibility explanations to the courts about unusual event and reserve explanatory assertions for more routine or mundane events. Actions can be out of character even for someone living longterm with a mental disorder so that their actions are atypical for that individual even with their distorted belief system. How much causal contribution does a mental disorder have to make before it exculpates sufficiently to avoid a punitive sentence? As Buchanan and Zonana argue, psychiatrists may be able to offer the courts reasons why someone acted, without offering causal explanations. And whether this is sufficient to meet the judge's threshold in accepting a plea that the prosecution make him sure of their assertions is another matter. Being thoroughly convinced of a possibility explanation may not be sufficient to make one sure.

In these uncertain areas there must also be a concern that the ability to form a rational judgment gets judged by the outcome; crudely, since it can't be rational to kill three children (there will be alternatives) it must be irrational and Clarence must have been overwhelmed. This looks like post hoc reasoning.

If psychiatrists are in difficulty with respect to assessing causation are lawyers in a better position? Whilst Clarence's mentally disordered actions were a factual 'but for' cause, was there legal causation? That she was convicted says yes: culpability is fairly attributable to her. But how much does she bear? Again, this

41 s.2 diminished responsibility no longer requires responsibility to be diminished; rather there has to be a substantial impairment of the ability to do one or more of three things (understand nature of conduct, to form a rational judgment, exercise self control) and that impairment has to cause or be a significant contributory factor, and thereby provide an explanation for the conduct.

42 Lord Parker CJ, Byrne (1977) 65 Cr App R 242.

43 Kabn [2009] EWCA Crim 1569. 
looks, in the context of mental disorder, impossible to assess since the courts are seemingly prepared to attribute a very large role to mental disorder in outmanoeuvring all of the factors to which it would normally refer in order to assess culpability. Her blameworthiness is almost extinguished because the view is taken that from her disordered perspective she had no choice but to do what she did; but her responsibility, in the sense of being accountable, remains, in the prosecution's eyes, considerable: and that is again consistent with the causative role that her disordered actions played. But if the judge views this as causation without blame, then a custodial penalty cannot be right. And yet the prosecution must have regarded her actions as causative in a legal sense (i.e. responsible in large measure) and worthy of some element of blame (low culpability).

Would it be more helpful if diminished responsibility became diminished culpability? If responsibility is about causation and culpability about blame apportionment then maybe, given the tricky psychiatric issues around causation, it would be better to do away with responsibility. And leave the cognitive issues to bear on traditional blame apportionment criteria such as planning, prior fault and the targeting of vulnerable victims.

Alternatively, is it worth observing that prior criminality is seen as leading inexorably to future risk; prior mental disorder is not always, despite the possibility that both can recur. How exceptional is Clarence? And is this something to celebrate on behalf of mentally disordered offenders or lament on behalf of mentally disordered offenders?

\section{CAN THE COGNITIVE LITERATURE ADD INSIGHT?}

This is a bowdlerised - certainly highly selective - analysis on my part of the cognitive and behavioural science literature. But I hope it will provide some insights. Throughout it is important to recognise that exponents in this field acknowledge that many of our instinctive decisions are very good, so this is by no means intended as a demolition of judicial decision-making. The central issue is how to get people to make better decisions when the prevailing circumstances are likely to facilitate error.

It is also not a novel combination of literatures. The study of cognitive errors in judicial decision-making has been long established (Fitzmaurice and Pease 1986) and the application of dual-processing models of information handling has recent exponents (Harper and Hogue 2014). Such models (Evans 2008, Kahneman 2012) propose that people make decisions by resort to two distinct systems: a rapid sub-conscious heuristic based system which draws on experience and emotions (Kahneman's system 1); and a more deliberate, slow, rational and conscious reasoning process (Kahneman's system 2). But if system 1 makes a judgment it is harder for system 2 to change it because, as Kahneman asserts, the 
conscious system is an endorsing system rather than one which critically examines system 1's judgments. And that only becomes problematic where system 1's heuristics lead people to base decisions on stereotypical examples or to generalise unjustifiably from single case examples.

The literature is not without its own internal debates. For example, Kahneman (2012) and Gigerenzer (2002, 2014) are portrayed as if in opposition, with Gigerenzer arguing that Kahneman presents 'an unfairly negative view of the human mind' (Adams 2014). Gigerenzer would assert that greater access to data leads to greater complexity and uncertainty (and as the above analysis shows, there is not a shortage of detailed information presented in these cases); and that in these circumstances defensive decision-making results in people basing their decisions by drawing, perhaps selectively, on the available data, but in so doing making inferior choices. Although these assertions are value-laden, there is some resonance with the risk-averse decision-making which characterises the disposal of mentally disordered offenders.

Gigerenzer would favour educating people about statistical probability so that they can become more 'risk savvy'; but he is in no sense dismissive of the important role of heuristics - rules of thumb - in decision-making where competing risks can't be gauged. And Kahneman would certainly favour a better understanding of role of these heuristics.

In situations where judgments have to be made under conditions of uncertainty, as is routinely the situation where the s.45A is contemplated, Tversky and Kahneman (1974: 1124) would identify three important heuristics as making decisions more economical and effective; and thus attractive at some level - even if non-consciously - to decision-makers. These heuristics are not claimed necessarily to lead to better outcomes; indeed, as Tversky and Kahneman (1974: 1124) elaborate, they rather lead to systematic and predictable errors. The three heuristics are:

(i) Representativeness - does X belong to class Y?

(ii) Availability of instances or scenarios - for example, where one is asked to assess the frequency of $\mathrm{X}$ or the plausibility of a particular development a decision-maker will draw on readily available stereotypes and exemplars.

(iii)Adjustment from an anchor - useful in sentencing where some new judgement is made from a relevant value.

All three are problematic in s.45A decisions. The hybrid nature of the disposals means that the offenders do not naturally fall into either a treatment or a punishment group for reference purposes. But their own grouping, that of hybrid cases, is so small as to make the availability of other similar cases for comparison purposes problematic. There is thus a very narrow frame of reference.

This may not be a disadvantage if misplaced representativeness is avoided. But equally, treating each case as a unique example must make judgements peculiarly challenging. And it permits cases to be categorized as falling at one end 
or the other of the treatment-punishment spectrum. The reliance on one or two key cases is not antipathetic to legal reasoning; but it is unfortunate that here systematic errors may be being built into subsequent decisions.

The use of anchoring techniques may also be problematic as there are no obvious anchoring points in choosing between therapy and punishment. This is unlike conventional sentencing decisions where there are either sentencing guidelines with the appropriate starting point and category-range based on an assessment of harm and culpability using predetermined factors, and then adjusted by further factors which either increase seriousness or serve to mitigate; or possible anchor points indicated by counsel or in pre-sentence reports. Instead, there are a number of somewhat contradictory Court of Appeal judgments, and a great deal of discretion is left to the judge to override the views of the clinicians giving evidence to the court. Finally, trial judges make their decisions alone, so do not even have the tempering effects of group decisions. Making a one-off decision alone is hazardous.

The second relevant area of decision-making, beyond the role of heuristics, concerns the relative absence of feedback. There are, of course, the appeal cases, but these were slow in building-up and, aside from them, there will be very little feedback to the judges as to whether they have got their decisions right. The timeframe for outcomes is so prolonged that many of the judges will understandably have moved on from the case or even retired before an outcome is known; if it ever is.

Third, as Gigerenzer (2002) would observe, we overestimate and overweight unlikely events: since it is cognitively easy to imagine disaster, and harder to imagine normalcy in the frame of a pre-existing horrific sequence of events, the likelihood of reoccurrence looks more probable than it should. And certainly more probable than it should when making allowances for the passage of time and the positive effects of treatment.

Fourth, mentally disordered offenders raise the spectre of fear in most of us. Much of this is unwarranted, since for many their general offending is made no better or worse by their disorders. But the s.45A group are particularly dreadful in their histories: both very severe disorders and extremely violent and frightening offending cannot do anything other than make decision-makers extremely cautious in their decisions. Here, as Jonathan Haidt (2001) has observed the 'emotional tail wags the rational dog'; rational reasoning won't necessarily change someone's mind in relation to a decision based on deeply held or intuitively formed moral values. People think that their judgments are based on rational reasons already and therefore changing them in response to alternate rational reasons is improbable. System 2's reflective reasoning is primarily an endorsing mechanism: if system's 1's conclusions based on an emotional response or on a limited experiential base is wrong, system 2 will not necessarily correct it.

Fifth, with the passage of time things do change. It is very difficult to look into the future and say, in a decade or more, what the comparative effectiveness 
of supervision under the probation service on life licence, or under medical supervision on conditional discharge, is likely to be. Undoubtedly, the probation service has been subject to significant change; and arguably much more change than has the conditional discharge process, which is subject to ministerial oversight with the Mental Health Unit at the Ministry of Justice being a repository of cautious and experienced decision-making (see Tessa Boyd-Caine 2010). But the decisions in the s.45A sample still seem to favour the prison-parole route on the basis of very little evidence about outcomes, and on assumptions that having a tougher release threshold and lower threshold for recall will result in better outcomes.

Sixth, evaluating these decisions is also problematic. At one level, the key question is: was the right allocation made? But at another, issues of process are critical since, when in error, they can generate appeals in both the short and long term (and cases involving mental health issues are unusual in having a long tail of appeals). I cannot judge whether the courts are doing better or worse than usual with respect to this category of case, by comparison with other sentencing decisions, but the number of appeals does look high given the infrequency with which the orders are made. And this might suggest either some process errors, where decisions are not upheld, or a sense that justice has not been done, where decisions are appealed but ultimately upheld.

Seventh, simple, concrete stories are more compelling when they seemingly explain events. This over-weights people's attributes and their attributed intentions; it is clearly the case that the courts give considerable emphasis to any intention made out by the prosecution as underpinning partial culpability. Yet the role of chance in any event is underestimated and we overestimate positive events whilst failing to notice the countless things that did not happen. Understandably, when someone is killed or seriously injured that event will dominate and frame the decision; but it is very hard to know whether an event is likely to be repeated if the unique factors that predated it are significantly attributable to illness or happenstance and only partially attributable to conscious, rational, determined decision-making by the mentally disordered offender. Hindsight bias merely adds to this sense that we understand why things happen as they did.

Finally, and drawing on Kahneman's (2012) analysis, it is equally problematic that our decision-making strategies favour making decisions on the basis of very little information, and we then seek confirmation of those decisions, since coherence and confidence are the watchwords of intuitive decision-making. Thus, if we frame a mentally disordered offender as dangerous, and this is easy to do, then we are likely to be cautious in our preferred outcomes. And, to reiterate, system 2, our more considered rational reflective being, is prone to endorsing system 1's intuitive decisions rather than critically examining them. This is not routinely a problem, since as Kahneman notes (2012: 416) system 1 is the source of most of what we do right (as well as much of what we do wrong). But if decision-making, and especially erroneous decision-making, is outcome driven it can be a problem. 
The notion of outcome driven decision-making is one which I have examined in detail in my much earlier work on Mental Health Review Tribunals (Peay 1989: 182-184), but it is also one which has been gaining traction in the more recent philosophical literature on memory and choice; choices can be made at an intuitive or non-conscious level, whilst plausible reasons for them postdate the choice (Bortolotti 2011). ${ }^{44}$ But again, the reality may be more nuanced, for as Bortolotti concludes about the 'choice' between intuitive and reflective decisionmaking (2011: 309) 'analysis and habit co-exist in a complex relationship whenever experts make choices'.

\section{CONCLUSIONS}

The court's observation in Abmed that this was somebody who was ill who required treatment and not a criminal who required punishment goes to the heart of the matter. How are offenders with mental disorder to be so classified? The answer derived from this analysis of s.45A cases suggests that partial culpability a concept so fluid as to satisfy the policy desire for greater flexibility - is used as a vehicle for the future management of perceived risk. But its very lack of concreteness results in some incoherence in the cases and significant disparities between the sentencing and disposal of mentally disordered offenders. Moreover, potentially discriminatory practices could arise when comparing s. $45 \mathrm{~A}$ offenders with non-disordered offenders, with respect to an assessment of the risk of future non-disordered offending. Finally, it is clear that s.45A has been used increasingly opportunistically as such orders are attached to indefinite forms of life imprisonment. Here, risk management will always be by the Parole Board, so nothing is to be gained in terms of differing thresholds for release or recall. The s.45 order must simply be used as a means of accessing a treatment setting on an immediate basis, rather than using a s.47 transfer order (which can be made in advance, or can be significantly delayed).

Notions of partial culpability can be traced back to the decision in Birch in 1989, with the House of Lords in Drew giving this extra gravitas. But the analysis is problematic since everyone who is not either acquitted or found not guilty by reason of insanity will bear some degree of responsibility for their actions. The courts have variously pointed to, for example, pleas to offences involving intention, or jury findings to that effect. In formal diminished responsibility manslaughter cases they have referred to significant degrees of responsibility or of responsibility not being wholly extinguished. And, of course, for the s.45A order there is an implicit assumption that the residual responsibility should be high (or

44 See also a fascinating discussion on The Forum, BBC World Service, $8^{\text {th }}$ December 2014 on 'Unintended Consequences' involving Professor Bortolotti, a philosopher of cognitive sciences. 
as high as is possible in the space remaining between full responsibility and significant responsibility or responsibility not being wholly extinguished). And the courts have pointed to the defendant's behaviour in the run up to the offences or in their aftermath as signalling residual culpability.

But all of these assessments are, of course, being made about offenders with mental disorder; and in the tranche of more recent cases these are primarily offenders in acute psychotic states at the point at which they offend - which perhaps explains the clinical preference in a number of them for a s.37/41 order but it also brings into question the extent to which offenders truly appreciated the consequences of their pleas. One assumes that these were explained by counsel, but this cannot ever be easy. Nor can it be easy for counsel, or the court, to be fully confident that the implications have been understood.

The question then becomes why in some cases is a decision made not to focus on partial culpability but to focus on the offender's disorder as being 'wholly responsible' for the offence, that is to assert that the offences would not have been committed but for the presence of the disorder. There is perhaps a drift towards this in cases where the offender was young, or suffering from autism, or had no previous convictions (and a young age militates against prior convictions). And a striking shift away from it where the offence was particularly horrific, as are many of these offences, and there was prior offending. But the awfulness of their offences cannot be the sole explanation for the avoidance of attributions of partial culpability as many offenders receive a s.37/41 order despite such offending. Equally, many offenders never have their mental states fall into the psychiatric spectrum, despite the awfulness of their offending. ${ }^{45}$ And in some cases the arbitrariness of it gets reflected in such remarks in Fox as 'the judge must have found partial culpability because he made an order for s.45A'.

Undoubtedly, and over time, the arguments about the differing methods of release, supervision and recall by the Parole Board of those on custodial sentences have clarified. There has been clinical resistance to the notion that s.37/41 conditional discharge is not the preferable method of release for those who have mental disorder and have offended (see, for example, Fox above) and the court has countered by suggesting that there is no reason why the Parole Board and life licence arrangements should not enhance their arrangements to match those of clinical release. Clinicians have, of course, on occasion resorted to the argument about s.45A being a useful order for preventing 'bed-blocking' - the kinder term for medical warehousing. Conversely, they have improved their arguments, for example in Fort, about the improbability of risky release given the prior need for extended symptom-free periods and the pre-requisite of a structured form of release into the community via decreasing levels of security to manage offenderpatients and any mounting stress.

45 For a number of examples see the counting dead women website at
http://kareningalasmith.com/counting-dead-women/. 
So this is a tale of a shift from uncertain treatability, through partial culpability and to 'flexibility' and then back to partial culpability as a vehicle for managing future risk. There is very little in the reasoning to suggest that the courts have concluded that these offenders deserve punishment; just that their partial culpability justifies a risk-based form of future control. Yet managing risk does not apply in this fashion to mentally ordered offenders (Szmukler and Rose 2013). Are such discriminatory practices justified?

Yet that still leaves another fundamental problem. Why are some offenders with partial culpability sent direct to hospital; and others given the perceived safety-net of the s.45A? And I can only reiterate that I believe this lies also in perceptions of unknowable and unquantifiable risk.

Two other sources of data might give some support to this analysis. First, over the period 1997-2014 the use of s.47/49 orders has increased which might indicate that more mentally disordered offenders are sentenced to prison in the first instance and then transferred at some point thereafter (possibly because their disorder may not have been manifest at the point of sentence). This may be indicative of a more cautious and/or more punitive approach to sentencing mentally disordered offenders. Equally, the use of s.37/41 orders have also fluctuated over that period, albeit there has been generally an increase over time, which might indicate a more therapeutic tendency on behalf of the courts. However, it is also notable that s.37 orders previously outnumbered s.37/41 orders, but that has not been so since $2006 / 7$, which may again indicate a shift to a more cautious approach. ${ }^{46}$ In this context, the s.45A orders, given that they are so small in number, may indicate either the courts are sending to hospital in the first instance those they would previously have just given a custodial sentence; or that they are giving a sentence of imprisonment, plus treatment to those to whom they would previously have given s.37/41 hospital based disposals. It is impossible to know. Of course, if the courts were just being cautious about treatability this could be resolved through greater use of interim hospital orders; but the numbers of these orders are not separately recorded and arguably have been underused. ${ }^{47}$

And a paragraph peppered with words such as might, may and impossible to know is a justification for seeking to talk directly to members of the judiciary about their understanding of the difficulties they face in sentencing or disposing of mentally disordered offenders. Such research would cast a significant light on why so many mentally disordered offenders are to be found within our prison population.

The second area of insight into these imponderable questions about risk and mental disorder can be gleaned from the House of Lords decision in Drew. Their

\footnotetext{
46 See HSCIC (2014).

47 In the annual inpatient statistics they are combined with s.44 (which deals with aspects of committal to hospital by the Magistrates courts) and the repealed s.46. (see HSCIC 2014).
} 
Lordships were careful not to endorse a shift to the use of prison in preference to hospital orders, albeit they noted the perceived problems with release. However, that caution does not seem to have been reflected in the reasoning in those cases where s.45A orders have been upheld. The tiny numbers make any conclusions impossible, other than to note the infrequency with which the House of Lords' cautionary words about disposal have been cited, by comparison with the precautionary words about release mechanisms. And it is notable that both the House of Lords in Drew and the Court of Appeal in Staines expressed some frustration that the s.45A order was not then available to those offenders with mental illness, and remains unavailable to those under 21. For an order which has been so little used, do the courts' observations reflect a wider frustration with disposal options when dealing with mentally disordered offenders?

However, if this picture of risk-based, culpability-attributing reasoning applies in equal measure to the sentencing of other mentally disordered offenders, it is perhaps not surprising that so many such offenders end up in prison, and not in hospital, as perhaps the authors of the Mental Health Acts 1959 and 1983 humanely envisaged. 


\section{References}

Adams T (2014) Nudge Economics: Has Push Come to Shove for a Fashionable Theory? The Observer June 1.

Bortolotti L (2011) Does Reflection Lead to Wise Choices? Philosophical Explorations 14, 3: 297-313.

Boyd-Caine T (2010) Protecting the Public? Detention and Release of Mentally Disordered Offenders. Routledge, Abingdon.

Buchanan A and Zonana H (2009) Mental Disorder as the Cause of a Crime. International Journal of Law and Psychiatry 32: 142-146.

Eastman N and Peay J (1998) Sentencing Psychopaths: Is the 'Hospital and Limitation Direction' an Ill-Considered Hybrid? Criminal Law Review 93-108.

Evans J (2008) Dual-processing Accounts of Reasoning, Judgment and Social Cognition. Annual Review of Psychology 59: 255-78.

Gigerenzer G (2002) Reckoning with Risk: Learning to Live with Uncertainty. Penguin, London.

Gigerenzer G (2014) Risk Savy: How to Make Good Decisions. Penguin, New York.

Harper C and Hogue T (2014) A Prototype-Willingness Model of Sexual Crime Discourse in England and Wales. Howard Journal of Criminal Justice 511-524.

Home Office/Department of Health (1996a) Mentally Disordered Offenders Sentencing and Discharge Arrangements: A Discussion Paper on a Proposed New Power for the Courts.

Home Office/Department of Health (1996b) Protecting the Public: The Government's Strategy on Crime in England and Wales, Cm 3190, March 1996.

HSCIC (2013) Inpatients Formally Detained in Hospitals under the Mental Health Act 1983, and Patients Subject to Supervised Community Treatment. Annual report, England, 2013.

HSCIC (2014) Inpatients Formally Detained in Hospitals under the Mental Health Act 1983, and Patients Subject to Supervised Community Treatment. Annual report, England, 2014. 
Haidt J (2001) The Emotional Dog and Its Rational Tail: A Social Intuitionist Approach to Moral Judgment. Psychological Review 108.4: 814-834.

Hebenton B and Seddon T (2009) From Dangerousness to Precaution: Managing Sexual and Violent Offenders in an Insecure and Uncertain Age. British Journal of Criminology 49, 3: 343-362.

Kahneman, D (2012) Thinking, Fast and Slow. Penguin, London.

Kahneman D and Tversky A (1984) Choices, Values and Frames. American Psychologist 39, 4: 341-350.

Mackay R (2010) The New Diminished Responsibility Plea. Criminal Law Review 290-302.

Ministry of Justice (2008) Mental Health Act 2007: guidance for the courts on remand and sentencing powers for mentally disordered offenders. MOJ March.

Ministry of Justice (2010) Statistics of Mentally Disordered Offenders 2008.

Peay J (1989) Tribunals on Trial: A study of decision-making under the Mental Health Act 1983. Clarendon Press, Oxford.

Peay J (2011) Mental Health and Crime. Routledge, Abingdon.

Peay J (2014) Imprisoning the Mentally Disordered: A Manifest Injustice? Law Department Working Papers series 7/2014.

Peterson J, Skeem J, Kennealy P, Bray B, and Zvonkovic A (2014, April 14). How Often and How Consistently do Symptoms Directly Precede Criminal Behavior Among Offenders with Mental Illness? Law and Human Behavior, 38: 439-449.

Reed J (1994) Report of the Department of Health and Home Office Working Group on Psychopathic Disorder. DoH/Home Office, London.

Seddon, T. (2007) Punishment and Madness: Governing Prisoners with Mental Health Problems. Routledge, Abingdon.

Skeem J, Manchak S and Peterson J (2011) Correctional Policy for Offenders with Mental Illness: Creating a New Paradigm for Recidivism. Law and Human Behavior, 35: 110-126.

Szmukler G and Rose N (2013) Risk Assessment in Mental Health Care: Values and Costs. Behavioural Sciences and the Law 31: 125-140. 
Tversky A and Kahneman D (1981) The Framing of Decisions and the Psychology of Choice. Science, New Series, 211, 4481: 453-458.

Tversky A and Kahneman D (1974) Judgment under Uncertainty: Heuristics and Biases. Science, New Series, 185, 4157: 1124-1131. 